\title{
Commercial viability of locating pelagic longline branchline weights at the hook to reduce seabird bycatch
}

\author{
Eric Gilman ${ }^{1, *}$, Stephen Beverly ${ }^{2}$, Michael Musyl ${ }^{3}$, Milani Chaloupka ${ }^{4}$ \\ ${ }^{1}$ Pelagic Ecosystems Research Group, Honolulu, Hawaii 96822, USA \\ ${ }^{2}$ Fisheries consultant, Mont Dore Sud 98809, New Caledonia \\ ${ }^{3}$ Pelagic Research Group, Honolulu, Hawaii 96816, USA \\ ${ }^{4}$ Ecological Modelling Services Pty Ltd \& Marine Spatial Ecology Lab, University of Queensland, St. Lucia, Queensland 4067, \\ Australia
}

\begin{abstract}
Bycatch in pelagic longline fisheries threatens the viability of some seabird populations and reduces fishing efficiency. The mass of a branchline fishing weight and its distance from the hook significantly explain seabird catch risk during setting and hauling. We surveyed Hawaii tuna longline fishers to obtain their perspectives on the practicality, safety and economic viability of alternative designs which place weights adjacent to hooks instead of conventional designs with weighted swivels attached $0.6 \mathrm{~m}$ from the hook. We conducted experimental fishing to explore the commercial viability of a combination weighted swivel attached to the eye of the hook. We used a Bayesian random effects meta-analytic regression modeling approach to estimate pooled expected species-specific log relative risk of capture on conventional, as opposed to experimental, branchlines. There were significant decreases in catch rates on experimental branchlines of $54 \%$ (95\% highest posterior density interval [HDI]: 34.3 to 73.8 ) for retained species and $28 \%$ (95\% HDI: -7.5 to 93.3 ) for discarded species. For about $10 \%$ of experimental weighted hooks, the point of the hook tangled on the swivel, likely contributing to lower catch rates and making it more difficult for crew to coil branchlines. We identify additional possible factors explaining why the experimental gear reduced catch rates. The study demonstrates the benefits of stakeholder scoping to determine bycatch mitigation options with the highest promise for practicality, economic viability and safety, as well as benefits of conducting a pilot study to assess commercial viability to determine if a full experiment to assess bycatch mitigation efficacy is warranted.
\end{abstract}

KEY WORDS: Bycatch · Longline fisheries $\cdot$ Seabird $\cdot$ Tuna

\section{INTRODUCTION}

Capture in global pelagic longline fisheries threatens the viability of some seabird populations (Véran et al. 2007, Anderson et al. 2011, Phillips et al. 2016), while bait loss to scavenging seabirds and handling incidentally caught seabirds reduces fishing efficiency (Brothers et al. 1999, Gilman et al. 2005, Løk-

${ }^{*}$ Corresponding author: fisheriesresearchgroup@gmail.com keborg 2011). Hawaii's tuna longline fishery annually catches hundreds of seabirds, primarily Laysan albatross Phoebastria immutabilis and black-footed albatross P. nigripes (Gilman et al. 2008, 2016, NMFS 2017). Seabird catch levels have been significantly increasing in Hawaii's tuna longline fishery over the past decade, likely due to increasing temporal trends in fishing effort and black-footed albatross catch

(C) The authors 2020. Open Access under Creative Commons by Attribution Licence. Use, distribution and reproduction are unrestricted. Authors and original publication must be credited. 
rates (Gilman et al. 2016, Gilman \& Ishizaki 2019). The rise in catch rates may have resulted from changes in seasonal and spatial distribution of fishing effort and an increase in the number of albatrosses attending Hawaii longline vessels, possibly in response to variability in ocean productivity in the north Pacific Ocean linked to inter-annual and decadal climate cycles and climate change (Gilman et al. 2016, Gilman \& Ishizaki 2019).

Numerous gear technology methods have been demonstrated to reduce seabird bycatch in Hawaii and other pelagic longline fisheries, including branchline weighting designs (Gilman et al. 2005, Hall et al. 2017, ACAP 2019, Gilman \& Ishizaki 2019). The mass of a branchline fishing weight and the weight's distance from the hook significantly affect seabird catch rates during setting (Gilman et al. 2008, Melvin et al. 2013, 2014, Robertson et al. 2013, Santos et al. 2019) and hauling (Gilman et al. 2014a) in pelagic longline fisheries. These 2 variables affect the sink rate of baited hooks and concomitant availability to seabirds during gear setting. During setting, the closer a weight of a given mass is to the hook, the less time it takes for the weight to affect the hook's sink rate near the surface and the less time baited hooks are available to surface-foraging seabirds (Robertson et al. 2013, Jiménez et al. 2019). Similarly, during hauling, the closer a weight is to the hook, the more likely the weight will reduce the availability of baited hooks to surface-foraging seabirds (Gilman et al. 2014a).

Some fishers, however, are reluctant to place weights close to hooks due to safety concerns. During gear haulback, when the branchline is under tension and the catch either severs the branchline or 'throws the hook' (the hook dislodges or is torn out of the catch), a weight close to the hook can fly back at the vessel at high velocity as the branchline recoils, which can cause serious injuries and fatalities (Gilman et al. 2005, 2014a, McCormack \& Papworth 2014, Pierre et al. 2015, Rawlinson et al. 2018). Furthermore, compared to conventional monofilament leaders with weighted swivels crimped onto branchlines above the leader, placing a weight at the hook would increase the rate of losing weights when the catch severs the leader and when crew cut branchlines to release catch in the water (Robertson et al. 2013, Pierre et al. 2015, Gilman et al. 2018), and would result in this additional gear component being on terminal tackle attached to escaped animals.

While the initial sink rate of baited hooks near the sea surface is important in explaining the catch risk in longline fisheries in all regions and for surface foragers and deep-diving seabird species alike, this initial sink rate is particularly important in Hawaii's longline fisheries due to the seabird species complex that interacts with the fishery. Laysan and blackfooted albatrosses have relatively limited diving capacities (Prince et al. 1994), typically only making body thrusts to reach prey near the surface. Blackfooted albatrosses make dives to a mean depth of $0.6 \mathrm{~m}( \pm 0.2 \mathrm{~m} 95 \% \mathrm{CI})$ and have a maximum diving depth of about $2.5 \mathrm{~m}$ (Kazama et al. 2019). In addition, secondary interactions during setting, where deep-diving seabird species access baited hooks at depth and bring them to the surface where albatrosses and other larger, surface-foraging seabird species are then able to access the terminal tackle and become captured (Jiménez et al. 2012), has not been reported in Hawaii's longline fisheries (Gilman et al. 2005, 2014a, 2016). Baited hooks sink below the typical diving threshold of black-footed and Laysan albatrosses within a fraction of a second: a 15/0 circle hook, baited with a small species of pelagic 'forage' fish, with a $45 \mathrm{~g}$ weight attached $0.6 \mathrm{~m}$ from the hook, sinks to $0.6 \mathrm{~m}$ in about $0.6 \mathrm{~s}$ (Brothers \& Gilman 2006). Thus, seabird catch risk in Hawaii's longline fisheries may be highest at the moment baited hooks contact the sea surface during setting, and when crew bring baited hooks close to the surface during hauling (Gilman et al. 2014a). In this fishery, baited hook sink rates over the initial ca. $1 \mathrm{~m}$ of the surface likely is where seabird catch risk occurs, and not to $10 \mathrm{~m}$, which has been used for assessments of the effect of baited hook sink rate on the catch risk of Procellaria petrels in studies of southern hemisphere longline fisheries (e.g. Barrington et al. 2016). These observations support the hypothesis that placing weights at the hook instead of the predominant design in Hawaii's tuna longline fishery of attaching $45 \mathrm{~g}$ weighted swivels at the end of a $0.6 \mathrm{~m}$ wire trace (leader), would reduce Laysan and black-footed albatross catch risk.

As a precursor to testing this hypothesis, this study identified alternative branchline designs that place weights immediately adjacent to the hook. We surveyed Hawaii longline fishers to obtain perspectives on the relative practicality, safety and economic viability of the alternative branchline weighting designs, and conducted experimental fishing to explore the commercial viability of one of the designs. Collaboration and direct involvement of fishers in bycatch mitigation research is effective both at identifying promising solutions as well as obtaining a sense of ownership and uptake for 
changes in fishing methods and gear to reduce vulnerable species bycatch (Gilman et al. 2005, Hall et al. 2007). The study identified candidate branchline weighting designs that place weights at the hook that are potentially suitable for use in global tuna longline fisheries, and assessed the commercial viability of one of the more promising designs, contributing to mitigating seabird bycatch in pelagic longline fisheries.

\section{MATERIALS AND METHODS}

\subsection{Alternative branchline weighting designs}

To identify alternative designs that enable placing pelagic longline branchline weights immediately adjacent to the hook during setting, the Western and Central Pacific Fisheries Commission's Bycatch Management Information System online database of references, https://www.bmis-bycatch.org/references, was searched by filtering for species group: seabirds; fishing gear: longline; and mitigation technique: 'line weighting and bait sink rate.' The Consortium for Wildlife Bycatch Reduction's online database of references (https://www.bycatch.org//) was searched for relevant studies and filtered for hook-and-line fishing gear and seabird species, for both field and non-field studies. A Boolean search string using various combinations of the terms longline, seabird, weight, weighting, branchline, line, sink rate, pelagic and bycatch, as well as various operators, was conducted in Google Scholar. We then reviewed reference lists of relevant publications and reports. Longline fishers in Hawaii were asked to identify new branchline designs, and one of the authors (S.B.) suggested inclusion of a 'sliding egg sinker' design.

\subsection{Scoping}

Twelve longline fishermen, who collectively own and work on about half of the active vessels in Hawaii's tuna longline fishery, were interviewed and asked to provide their perspectives on the practicality, safety and cost of 4 alternative branchline weighting designs (Fig. 1). We employed non-probabilistic sampling techniques. The fishermen were shown samples and provided with a summary and cost information for each of the 4 alternative designs. The predominant conventional branchline design used in Hawaii's tuna longline fishery is to attach a $45 \mathrm{~g}$ weighted swivel to the end of a $\sim 0.6 \mathrm{~m}$ wire leader (see Beverly et al. 2003 for a detailed description of conventional branchline designs, which in Hawaii's tuna fishery will look like Fig. 1c but with the weighted swivel moved to $0.6 \mathrm{~m}$ away from the hooks to the end of the wire leader). The 4 alternative designs are described below:

(1) Sliding egg sinker. Sliding egg sinkers can be used on wire leaders (Fig. 1a). An egg-shaped weight with a hole through the center is threaded onto the leader. The egg sinker slides freely along the leader. The weight may slide to the swivel when coiling branchlines into bins, possibly making storage easier. Branchlines with egg sinkers would cost about US \$0.20 more per branchline than the conventional design.

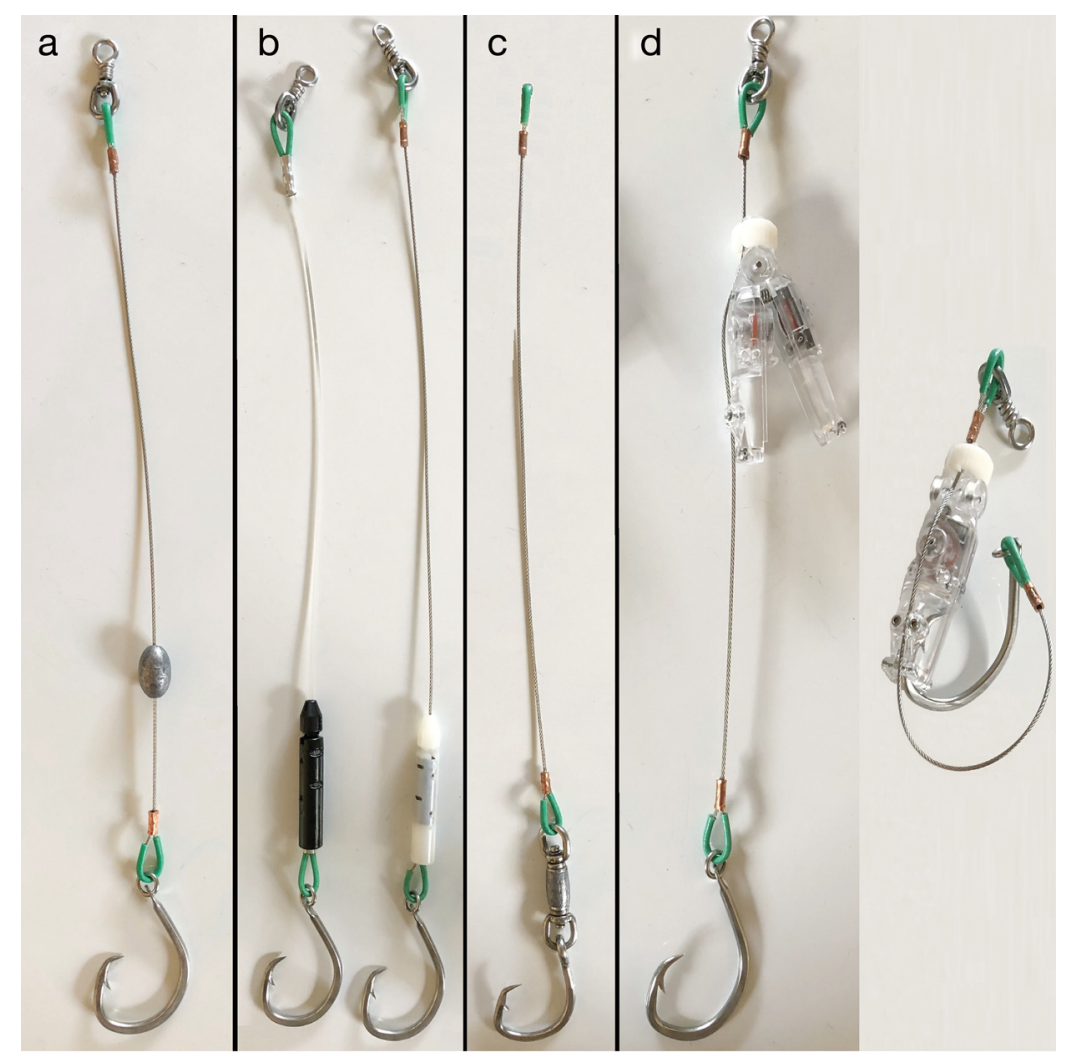

Fig. 1. (a) Sliding $45 \mathrm{~g}$ egg sinker, (b) $45 \mathrm{~g}$ Lumo Lead or GloLead on a monofilament and wire leader, (c) $45 \mathrm{~g}$ weighted swivel attached to the eye of the hook, and (d) Hookpod-mini when unattached (left) and attached (right) to the hook 
(2) Lumo Leads and GloLeads. Lumo Leads were obtained from FishTek Marine (https://www.fishtek marine.com/lumo-lead/) and GloLeads from Fishing International Supplies and Hardware (www.fishing international.com.au) (Fig. 1b). Non-luminescent versions are available (in order to reduce sea turtle catch risk, regulations for Hawaii's longline tuna fishery prohibit the use of light-emitting devices; US Government 2018). The weight is attached at a fixed location on the branchline using a screw cap. The devices are designed to slide on a monofilament leader when the branchline is under tension and the diameter of the line decreases. If the branchline severs when the monofilament line is under tension, then the Lumo Lead/GloLead slides as the line recoils, dissipating the velocity of the weight. When located within about $1 \mathrm{~m}$ of the hook, the device may slide off the branchline, reducing risk of injury to crew (Pierre et al. 2015, McCormack \& Rawlinson 2016, Rawlinson et al. 2018). During simulations of catch, throwing the hook with $40 \mathrm{~g}$ GloLeads and $45 \mathrm{~g}$ Lumo Leads attached $0.5 \mathrm{~m}$ from the hook on monofilament leaders, about two-thirds of hooks did not shear off, preventing the weight from safely sliding off (Rawlinson et al. 2018). When observed under commercial fishing conditions, when fish threw the hook, at lower velocities, Lumo Leads usually did not move or slid only a small distance on monofilament leaders, and likely had a minor effect on the velocity of the weight when the line recoiled (Pierre et al. 2015). While these weights can be used on wire leaders, when the branchline is under tension, the wire would not change diameter and the weight would not slide. Using these weights would cost about US $\$ 0.70$ more per branchline than the conventional design.

(3) Weighted swivel attached to eye of hook. A 45 $g$ weighted swivel can be attached directly to the eye of a hook (Fig. 1c). A crimped, looped end (with chaffing gear) would be placed at the end of the wire leader, which would connect to another loop at the end of the monofilament section of the branchline. This combination of a weighted swivel and hook, which is not commercially available and thus needs to be custom ordered, costs about US \$0.70 more than the conventional design.

(4) Hookpod-mini. The Hookpod-mini, which is made of polycarbonate with stainless steel springs, is attached at a fixed location on the branchline. During setting, crew attach the Hookpod-mini onto a baited hook, covering the hook's point and barb (Fig. 1d) (Goad et al. 2019, Hookpod 2019). A pressure release mechanism is set to open at a selected pressure (depth). Hookpods may slide on branchlines when under tension, but less so than Lumo Leads and GloLeads (Pierre et al. 2015). The Hookpod-mini weighs $49 \mathrm{~g}$ and has a depth rating of $1000 \mathrm{~m}$ (Hookpod 2019). Hookpod-minis have an estimated failure rate of about $1 \%$ based on observing 46000 deployments (about 1 trip by a Hawaii tuna longline vessel) due to devices being lost or damaged or having failed to open during trials in New Zealand's shallow-set longline fishery (of 46016 Hookpod-minis deployed during 130 sets, $0.6 \%$ were lost or broken, and $0.4 \%$ failed to open; Goad et al. 2019). During fly-backs (when a branchline recoils during gear haulback when catch is on the line and either the line breaks or the catch throws the hook), Hookpods had lower mean velocities than $40 \mathrm{~g}$ GloLeads, $45 \mathrm{~g}$ Lumo Leads and conventional weights crimped to branchlines, and tended to break into pieces when a fish threw the hook (Rawlinson et al. 2018). While the cost per branchline using Hookpod-minis with unweighted swivels would be about US \$6.58 more than the conventional branchline design, unlike other approaches to place weight at the hook, the Hookpod-mini has the potential to be adopted as a stand-alone measure to meet seabird bycatch mitigation methods (WCPFC 2018). Therefore, in some fisheries, use of Hookpods could eliminate the costs from required use of other seabird bycatch mitigation methods.

\subsection{Preliminary assessments}

A majority of surveyed fishers ranked the sliding egg sinker as their highest preference. To help select a design for the at-sea experiment, we conducted a preliminary assessment to determine whether the sliding egg sinker was consistently positioned at the hook during setting. The egg sinker design was assessed to determine the position of the weight during a simulation of setting when crew set a branchline either with the weight at the hook or at the clip end of a wire leader $0.6 \mathrm{~m}$ from the hook. Test branchlines were thrown either by holding the unweighted swivel $0.6 \mathrm{~m}$ from the hook or by holding the shank of the hook. The branchline was deployed from an elevation of between 3 and $5 \mathrm{~m}$ to simulate setting from the deck of a fishing vessel. When the terminal tackle reached the sea surface, the position of the egg sinkers on the leader was variable and did not consistently end up at or near the hook. When the sliding sinker was positioned at the swivel end of the leader, it tended to remain at this position. 
Based on the survey results and the preliminary assessment of the sliding egg sinker, the weighted swivel attached to the hook eye was selected for inclusion in the at-sea experiment. We conducted a preliminary assessment of this combination weighted swivel/hook design to determine its practicality for assemblage and storage in bins relative to conventional branchlines. The crew found no difference in constructing branchlines with the combination weighted swivels/hooks nor in coiling and storing them in bins, with no difference in the number of branchlines that could be stored in a bin.

\subsection{At-sea demonstration and experiment}

The weighted swivel attached directly to the hook eye was assessed on the Hawaii-based FV 'Kilauea' during 1 trip of 15 sets made between 16 April and 3 May 2020. There were 3780 hooks per set, with 28 hooks per basket (between 2 floats). OPI $10^{\circ}$ offset, stainless steel, forged 15/0 circle hooks were used. A hook with a weighted swivel weighed $62 \mathrm{~g}$ (17 g hook, $45 \mathrm{~g}$ swivel). The experimental design was balanced with 1890 branchlines of each of the 2 weighting designs deployed per set. During the first set, treatments were alternated every 2 branchlines, and the experimental and control treatments were then allowed to randomly mix during subsequent sets. The following was recorded for each catch: (1) species, (2) treatment it was captured on and (3) whether it was retained or discarded. The number of fly-backs that occurred with each treatment, and whether they were due to bite-offs or from a fish throwing the hook, was also recorded.

Cable ties were attached to the clips of experimental branchlines. When crew cut the monofilament section of a branchline above wire leaders to release a captured shark, the cable ties enabled crew to determine the terminal tackle design of that branchline. Furthermore, throughout the experiment, the cable ties enabled the crew to maintain equal numbers of experimental and control treatment branchlines.

We used a random-effects meta-analytical regression modeling approach (van Houwelingen et al. 2002) to estimate the species-specific log relative risk of capture on a control branchline as opposed to on an experimental branchline. The log relative risk effect size metric used here is a widely used standardized summary metric for comparative studies (Lajeunesse 2011). Specifically, we used the catch and effort from the 15 longline sets sampled in this fishing experiment for each of the 15 captured species. We then used those data to derive the speciesspecific log relative risk ratio and variance using the 'escalc()' function in the 'metafor' package for $\mathrm{R}$ (Viechtbauer 2010). We fitted a Bayesian regression model with Gaussian likelihood to those standardized effects sizes to estimate the overall log relative risk of capture on an experimental branchline, with species as the random effect - this is also known as a normal-normal hierarchical model and is especially useful for modeling studies such as ours with small sample sizes (Günhan et al. 2020). This model was fit using the Stan computation back-end (Carpenter et al. 2017) via the 'brms' interface for R (Bürkner 2017). We applied this model separately to the assemblage of retained species $(n=12)$ and then to the assemblage of discarded species $(n=3)$. We then summarized the results separately for the retained and discarded species in forest plots of the species-specific posterior densities to display the model-predicted mean posterior estimates and $95 \%$ credible intervals (see Schild \& Voracek 2015 for an overview of various forms of forest plot). We used the back-transformed posterior samples to calculate the percent risk reduction in catch risk for experimental branchlines. Here we used the highest posterior density interval (HDI) as our measure of uncertainty (Kruschke \& Liddell 2018). The HDIs were summarized from the posterior samples for each meta-analytic model fit using the 'tidybayes' package for R (Kay 2019). All assessments were conducted using $\mathrm{R}$ version 4.0.2.

At the end of the fishing trip, the captain and crew were interviewed to document their perspectives on the practicality, durability, safety and cost of the experimental design.

\section{RESULTS}

\subsection{Fisher survey}

Responses of the longline fishers to the survey on 4 alternative branchline weighting designs are summarized in Table 1. Fishers were also asked which of the 4 alternative designs, overall, considering practicality, safety and economic viability, they would prefer to use and why.

Eight fishermen preferred the egg sinker on a wire leader because this is the simplest and cheapest option, because it would not affect how many branchlines can be stored in a bin, and because it is durable. One respondent expressed highest preference for the egg sinker on a monofilament leader with no un- 
Table 1. Responses of Hawaii longline fishers $(n=12)$ to survey questions on the practicality, safety and economic viability of 4 alternative branchline weighting designs that place weight at the hook relative to their conventional branchline weighting design

\begin{tabular}{|c|c|c|c|c|}
\hline \multirow{3}{*}{$\begin{array}{l}\text { Question } \\
\text { (1) How would it affect building } \\
\text { branchlines? }\end{array}$} & \multirow[t]{2}{*}{ Branchline design } & \multicolumn{3}{|c|}{$\longrightarrow$ No. of responses } \\
\hline & & Easier & Harder & No effect \\
\hline & Egg sinker & 1 & 0 & 11 \\
\hline & Lumo Lead / GloLead & 0 & 0 & 12 \\
\hline & Weighted swivel attached to hook & 0 & 0 & 12 \\
\hline & Hookpod-mini & 0 & 1 & 11 \\
\hline \multirow{5}{*}{$\begin{array}{l}\text { (2) How would it affect your setting } \\
\text { and hauling operations, including } \\
\text { the number of hooks you deploy } \\
\text { per set? }\end{array}$} & & Easier & Harder & No effect \\
\hline & Egg sinker & 0 & 3 & 9 \\
\hline & Lumo Lead / GloLead & 0 & 0 & 12 \\
\hline & Weighted swivel attached to hook & 1 & 0 & 11 \\
\hline & Hookpod-mini & 0 & 12 & 0 \\
\hline \multirow{5}{*}{$\begin{array}{l}\text { (3) How would it affect the way you } \\
\text { store branchlines in bins, including } \\
\text { how many can be stored? }\end{array}$} & & Easier & Harder & No effect \\
\hline & Egg sinker & 0 & 2 & 10 \\
\hline & Lumo Lead / GloLead & 0 & 5 & 7 \\
\hline & Weighted swivel attached to hook & 0 & 5 & 7 \\
\hline & Hookpod-mini & 0 & 10 & 2 \\
\hline \multirow{5}{*}{$\begin{array}{l}\text { (4) How would it affect the risk to } \\
\text { crew safety? }\end{array}$} & & Reduce & Increase & No effect \\
\hline & Egg sinker & 2 & 6 & 4 \\
\hline & Lumo Lead / GloLead & 0 & 9 & 3 \\
\hline & Weighted swivel attached to hook & 0 & 9 & 3 \\
\hline & Hookpod-mini & 2 & 4 & 6 \\
\hline \multirow{5}{*}{$\begin{array}{l}\text { (5) How would it affect the rate of } \\
\text { damage and loss of terminal tackle? }\end{array}$} & & Reduce & Increase & No effect \\
\hline & Egg sinker & 0 & 3 & 9 \\
\hline & Lumo Lead / GloLead & 0 & 1 & 11 \\
\hline & Weighted swivel attached to hook & 0 & 0 & 12 \\
\hline & Hookpod-mini & 0 & 1 & 11 \\
\hline \multirow{5}{*}{$\begin{array}{l}\text { (6) How would it affect catch rates } \\
\text { of target species? }\end{array}$} & & Reduce & Increase & No effect/Do not know \\
\hline & Egg sinker & 3 & 0 & 9 \\
\hline & Lumo Lead / GloLead & 5 & 0 & 7 \\
\hline & Weighted swivel attached to hook & 4 & 0 & 8 \\
\hline & Hookpod-mini & 4 & 1 & 7 \\
\hline \multirow{5}{*}{$\begin{array}{l}\text { (7) How would it affect damage to } \\
\text { catch? }\end{array}$} & & Less & More & Same \\
\hline & Egg sinker & 1 & 0 & 11 \\
\hline & Lumo Lead / GloLead & 1 & 0 & 11 \\
\hline & Weighted swivel attached to hook & 1 & 0 & 11 \\
\hline & Hookpod-mini & 0 & 4 & 8 \\
\hline \multirow{5}{*}{$\begin{array}{l}\text { (8) Would it wear out and need to be } \\
\text { replaced at a higher, lower or same } \\
\text { frequency than conventional } \\
\text { branchlines? }\end{array}$} & & Lower & Higher & Same \\
\hline & Egg sinker & 0 & 2 & 10 \\
\hline & Lumo Lead / GloLead & 0 & 5 & 7 \\
\hline & Weighted swivel attached to hook & 0 & 0 & 12 \\
\hline & Hookpod-mini & 0 & 11 & 1 \\
\hline \multirow[t]{5}{*}{ (9) Is the higher cost unreasonable? } & & Yes & No & \\
\hline & Egg sinker & 0 & 12 & \\
\hline & Lumo Lead / GloLead & 1 & 11 & \\
\hline & Weighted swivel attached to hook & 1 & 11 & \\
\hline & Hookpod-mini & 11 & 1 & \\
\hline
\end{tabular}

weighted swivel because this is the simplest and cheapest option; use on a monofilament leader would address safety issues; and eliminating the swivel, plus allowing for the use of less expensive aluminum crimps that can be used on monofilament in place of more expensive copper crimps that must be used on wire leaders, would make it cheaper and easier to build branchlines.
Three respondents selected the weighted swivel attached to the hook on a wire leader as their highest preference because it does not affect practicality, the safety risk would be about the same as their conventional branchline design given how few fly-backs occur, it is more durable than the other options, and the higher cost is acceptable and might drop if there were sufficient demand. 
All 12 respondents indicated that, following the cost for the initial outlay, the second most important reason that they did not select the Hookpod as their preferred choice was that they believed it would reduce their fishing efficiency. They believed that the Hookpod would reduce the number of branchlines that can be stored in each bin. Because they lack deck space to add another bin, this would reduce the total number of branchlines deployed per set. They also predicted that having crew attach the Hookpod to hooks during setting would reduce their hook setting speed.

\subsection{At-sea demonstration and experiment}

The FV 'Kilauea' captured 1125 fish during the experiment. No seabirds or other non-fish species were captured. Fishers retained all captured tunas $(\mathrm{N}=100)$, billfishes $(\mathrm{N}=47)$, mahi mahi Coryphaena hippurus $(\mathrm{N}=31)$, monchong Taractichthys steindachneri $(\mathrm{N}=$ 25), opah (Lampris spp., $\mathrm{N}=13$ ) and wahoo Acanthocybium solandri ( $\mathrm{N}=22$ ), and about half (16 of 29) of the oilfish Ruvettus pretiosus. We refer to these species combined as retained species. Fishers discarded all captured blue shark Prionace glauca $(\mathrm{N}=78)$, lancetfishes (Alepisauridae spp., $\mathrm{N}=628$ ) and snake mackerel Gempylus serpens ( $\mathrm{N}=152)$, and we refer to these species combined as discarded species.

Fig. 2 presents forest plots summarizing the modelpredicted log risk ratios and the estimated pooled random effects for retained and discarded species. The overall random effects estimate of relative risk was significant for both retained and discarded species. The posterior probability of the overall effect being significant was $>99 \%$ for retained species and $94.2 \%$ for discarded species. There were significant decreases in catch rates on experimental branchlines for retained (53.8\%; 95\% HDI: 34.3 to 73.8 ) and discarded (27.8\%; $95 \%$ HDI: -7.5 to 93.3$)$ species.

The FV 'Kilauea' captain and crew found no differences between the conventional and experimental branchlines in assembly and deployment. The experimental branchlines were more difficult for the crew to coil into bins during gear haulback because periodically, when holding the crimped loop at the mainline-end of the wire leader, the line would slip through their hands. In comparison, when coiling a conventional branchline, the crew hold the weighted swivel, which does not slip through their hands. Furthermore, during each haul, about $10 \%$ of experimental treatment branchlines had the point and barb of the hook snagged on the upper portion of the weighted swivel. The eyes of some of the experimental hooks were narrow, making it difficult for the crew to untangle the hook from the swivel.

No fly-backs were observed during the trip. The captain and crew perceived no difference in safety risk between the conventional and experimental treatments. They also perceived no difference in the rate of loss of terminal tackle or in branchline abrasion, and they did not observe a difference in damage to catch.

Overall, the captain and crew would choose not to use the experimental treatment because it substantially reduced catch rates of market species and made the haulback more problematic.

\section{DISCUSSION AND CONCLUSIONS}

We found that the experimental combination weighted swivel and hook had significantly lower catch rates for retained and discarded species than the conventional branchline design. One previous study assessed effects on tuna longline catch rates from placing a weight next to the hook: Robertson et al. (2013), who used monofilament leaders, found no difference in fish catch rates between $40 \mathrm{~g}$ luminescent LumoLeads at the hook versus $60 \mathrm{~g}$ luminescent LumoLeads at $3.5 \mathrm{~m}$ from the hook. Possible causes of the lower catch rates observed in the current study are:

- About $10 \%$ of experimental branchlines had hooks snagged on swivels, eliminating the ability to catch fish.

- A larger proportion of catch may escape from experimental than conventional branchlines during gear haulback if having the weight attached to the hook reduces pressure at the barb end of the hook, reducing the likelihood that the hook penetrates the tissue and catches the animal.

- Experimental hooks may have a different action (movement) in the water than conventional hooks. This might be due in part to some of the experimental hooks having narrow-diameter eyes, limiting the movement of the hooks.

- The proximity of the weight to the hook might have reduced attacks due to the visual detection of the weight. Pelagic predators may be able to readily see the weight and avoid preying on adjacent baited hooks, similar to hypothesized effects on catch risk of using more visible leader materials (Ward et al. 2008).

- The proximity of the weighted swivel to the hook might have caused the hook to more easily slide out of the mouth, increasing the rate of escapement. 

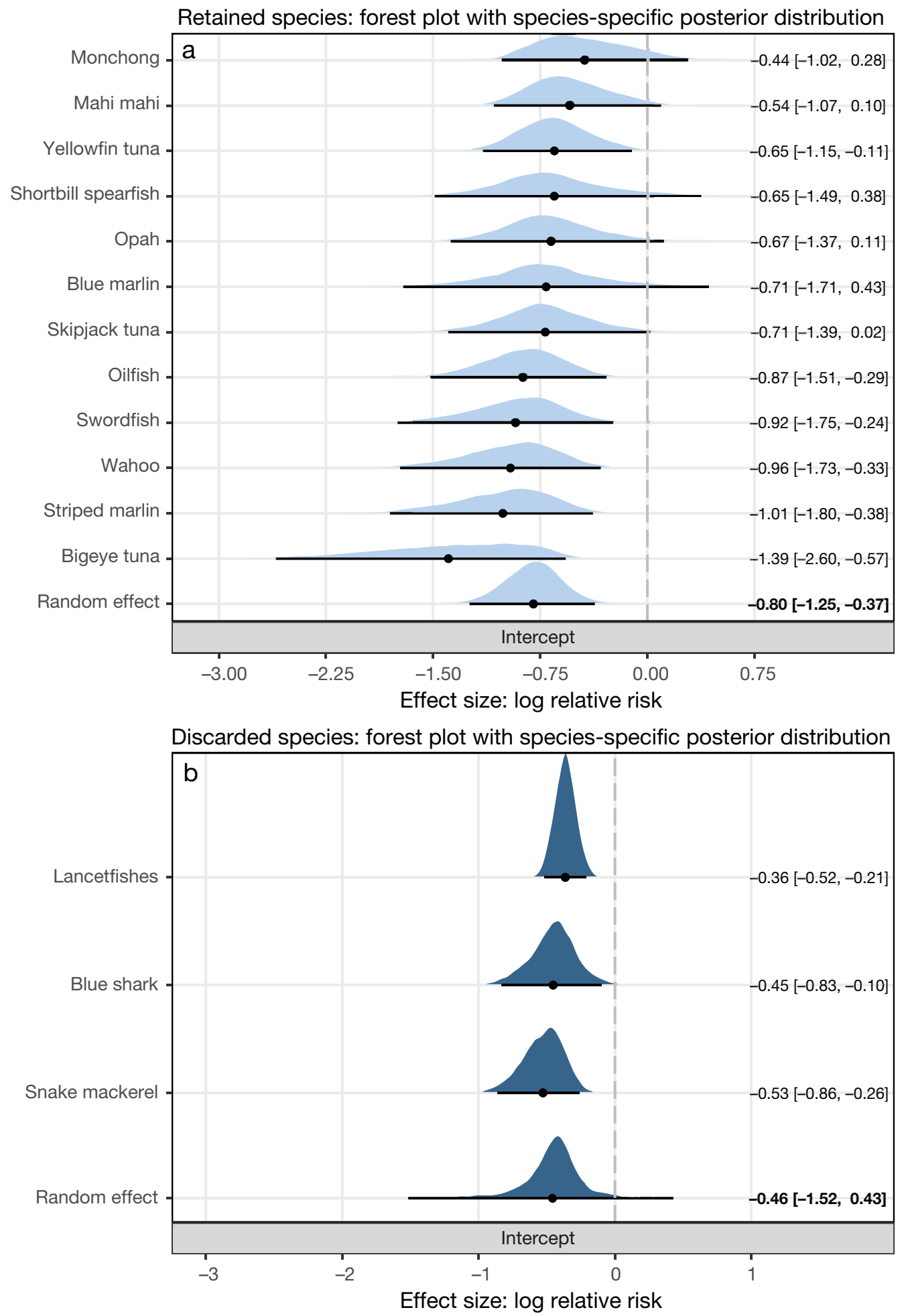

Fig. 2. Model-predicted log risk ratios for catch rates derived from (a) 12 species-specific effect sizes for retained species, and (b) 3 species-specific effect sizes for discarded species. Shrinkage estimates were derived using a Bayesian random-effects meta-analytic model with Gaussian likelihood. The polygons show the density of the posterior draws (effective sample size $=$ $20 \mathrm{k}$ ), the horizontal line is the $95 \%$ credible interval of the posterior draws, the solid dot is the mean of posterior draws shrunk towards the random effect estimate that is the pooled log risk ratio for combined species, and the dashed vertical line indicates no effect, with shrinkage estimates to the left of this line reflecting a lower catch rate on experimental branchlines with combination hook and weighted swivels than on conventional branchlines 
- While both the experimental and control hooks were both $10^{\circ}$ offset $15 / 0$ circle hooks, stainless steel and forged, they had slightly different dimensions. The control hook had a gradual offset, while the hook used in the experimental treatment had an abrupt offset between the bend and front of the hook (near the barb), which may have reduced the proportion of ingested experimental hooks that penetrated the mouth cavity.

While no fly-backs occurred during this experiment, more research is needed to determine whether locating weights at the hook increases safety risk relative to conventional designs. When attaching weights at the hook, relative to monofilament leaders, the use of wire leaders by Hawaii's longline fishery might result in minimal increased risk of injury from fly-backs because bite-offs are infrequent when wire leaders are used (Ward et al. 2008). However, leader material does not significantly explain safety risk from fly-backs when fish throw the hook, including when sliding weights are used on monofilament leaders (Pierre et al. 2015, Rawlinson et al. 2018). With weights at the hook, when fish throw the hook, both the hook and weight fly back at the vessel as a single object instead of as 2 objects separated by the length of the leader. Robertson et al. (2013) hypothesized that weights located at the hook would be underwater or at the surface when fish throw hooks, so that the weight and hook would pass through the water, reducing the recoil velocity. Most of the interviewed fishers reported that when sharks are captured, during haulback, the shark's head is typically near the surface or out of the water, so that when a shark throws a hook or the hook pulls out, the recoil velocity of a weight at the hook would not be dampened by passing through water. Observing and quantifying these occurrences is a research priority. There may be practices that effectively reduce risks from fly-backs, such as a method used by some Hawaii longline fishers of hauling branchlines over a bar to deflect or otherwise direct any fly-backs away from the working deck (ACAP 2014).

The ability to conduct compliance monitoring is another key criterion for assessing the suitability of alternative bycatch mitigation methods (Gilman et al. 2005). For fisheries with limited or no at-sea compliance monitoring, which is the case for most pelagic longline fisheries (Gilman et al. 2014b), surveillance using dockside monitoring can determine vessel compliance with some bycatch measures. Compliance monitoring of weighted swivels crimped to branchlines through dockside monitoring would be relatively robust; to move the weighted swivel further from the hook, fishers would have to rebuild branchlines twice per fishing trip. Similarly, compliance monitoring of sliding egg sinkers through dockside monitoring would be relatively effective; to secure the egg sinker on the leader away from the hook, fishers would have to add a crimp or other hardware to the leader and remove it prior to returning to port. Compliance monitoring of Lumo Leads, GloLeads and Hookpods through dockside monitoring would be relatively weak: during the fishing trip, crew could easily change the position of the Lumo Leads/GloLeads on leaders, and fishers might not attach Hookpods to hooks during setting. If, in the distant future, compliance monitoring occurs for $100 \%$ of pelagic longline fishing effort, such as through the use of electronic monitoring systems (Gilman et al. 2019, van Helmond et al. 2020), then branchline designs that currently do not support compliance monitoring will be better options. Until then, consideration of the capacity of a bycatch mitigation method to facilitate surveillance through dockside monitoring remains necessary.

We did not explore an exhaustive suite of alternative branchline designs that place weights at the hook. Additional new designs warrant investigation. For example, hooks integrated with weight and frozen bait infused with weight may hold promise.

This study demonstrated the benefits of stakeholder scoping to identify bycatch mitigation methods with the highest promise of meeting requirements for commercial viability. The study also demonstrated the utility of conducting a pilot study to assess commercial viability to determine whether proceeding with an experiment that assesses bycatch mitigation efficacy is warranted. Taking risks is essential for innovating and identifying effective seabird bycatch mitigation methods.

Acknowledgements. We are extremely grateful for the participation of Captain Michael Wild, first mate Aga Oliveros and the crew of the FV 'Kilaeua,' vessel manager Darleen Dela Cruz and owner Michael Ostendorp. We are thankful for the contributions of the following Hawaii longline fishermen to the survey: Scott Barrows, Jim Cook, Micah DeLong, John Haddad, Sean Martin, Richard McQuade, John Myking, Joe Viernes, Craig Yeackel, and 3 fishermen who chose to remain anonymous. We thank the journal editor and anonymous reviewers for their insightful and constructive comments. This study was made possible through a grant from the Bycatch Reduction Engineer Program, National Marine Fisheries Service, award number NA19NMF4720221.

\section{LITERATURE CITED}

ACAP (Agreement on the Conservation of Albatrosses and Petrels) (2014) Report of the Seabird Bycatch Working Group. 8th Meeting of the Advisory Committee. AC8 
Doc 12 Rev 1. Agreement on the Conservation of Albatrosses and Petrels, Hobart

ACAP (2019) ACAP review and best practice advice for reducing the impact of pelagic longline fisheries on seabirds. Agreement on the Conservation of Albatrosses and Petrels, Hobart

Anderson ORJ, Small CJ, Crozall JP, Dunn EK, Sullivan BJ, Yates O, Black A (2011) Global seabird bycatch in longline fisheries. Endang Species Res 14:91-106

Barrington J, Robertson G, Candy S (2016) Categorising branchline weighting for pelagic longline fishing according to sink rate. ACAP-SBWG7-Doc7. Agreement on the Conservation of Albatrosses and Petrels, Hobart

Beverly S, Chapman L, Sokimi W (2003) Horizontal longline fishing methods and techniques. A manual for fishermen. Secretariat of the Pacific Community, Noumea

Brothers N, Gilman E (2006) Technical assistance for Hawaii-based pelagic longline vessels to modify deck design and fishing practices to side set. Pacific Islands Regional Office, National Marine Fisheries Service, Honolulu, HI

Brothers N, Cooper J, Løkkeborg S (1999) The incidental catch of seabirds by longline fisheries: worldwide review and technical guidelines for mitigation. FAO Fisheries Circular No. 937. Food and Agriculture Organization of the United Nations, Rome

Bürkner P (2017) brms: an R package for Bayesian multilevel models using Stan. J Stat Softw 81:1-28

Carpenter B, Gelman A, Hoffman M, Lee D and others (2017) Stan: a probabilistic programming language. J Stat Softw 76:1-32

Gilman E, Ishizaki A (2019) Report of the workshop to review seabird bycatch mitigation measures for Hawaii's pelagic longline fisheries. Western Pacific Regional Fishery Management Council, Honolulu

Gilman E, Brothers N, Kobayashi D (2005) Principles and approaches to abate seabird bycatch in longline fisheries. Fish Fish 6:35-49

Gilman E, Kobayashi D, Chaloupka M (2008) Reducing seabird bycatch in the Hawaii longline tuna fishery. Endang Species Res 5:309-323

Gilman E, Chaloupka M, Wiedoff B, Willson J (2014a) Mitigating seabird bycatch during hauling by pelagic longline vessels. PLOS ONE 9:e84499

Gilman E, Passfield K, Nakamura K (2014b) Performance of regional fisheries management organizations: ecosystem-based governance of bycatch and discards. Fish Fish 15:327-351

* Gilman E, Chaloupka M, Peschon J, Ellgen S (2016) Risk factors for seabird bycatch in a pelagic longline tuna fishery. PLOS ONE 11:e0155477

Gilman E, Chaloupka M, Musyl M (2018) Effects of pelagic longline hook size on species- and size-selectivity and survival. Rev Fish Biol Fish 28:417-433

Gilman E, Legorburu G, Fedoruk A, Heberer C, Zimring M, Barkai A (2019) Increasing the functionalities and accuracy of fisheries electronic monitoring systems. Aquat Conserv 29:901-926

*Goad D, Debski I, Potts J (2019) Hookpod-mini: a smaller potential solution to mitigate seabird bycatch in pelagic longline fisheries. Endang Species Res 39:1-8

Günhan BK, Röver C, Friede T (2020) Random-effects metaanalysis of few studies involving rare events. Res Synth Methods 11:74-90
Hall M, Nakano H, Clarke S, Thomas S and others (2007) Working with fishers to reduce by-catches. In: Kennelly $\mathrm{S}$ (ed) By-catch reduction in the world's fisheries. Springer, Heidelberg, p 235-288

Hall M, Gilman E, Minami H, Mituhasi T, Carruthers E (2017) Mitigating bycatch in tuna fisheries. Rev Fish Biol Fish 27:881-908

Hookpod (2019) Simple, safe and effective seabird bycatch mitigation. Hookpod Ltd., Dartington

Jiménez S, Domingo A, Abreu M, Brazeiro A (2012) Bycatch susceptibility in pelagic longline fisheries: Are albatrosses affected by the diving behaviour of mediumsized petrels? Aquat Conserv 22:436-445

Jiménez S, Domingo A, Forselledo R, Sullivan B, Yates O (2019) Mitigating bycatch of threatened seabirds: the effectiveness of branch line weighting in pelagic longline fisheries. Anim Conserv 22:376-385

Kay M (2019) tidybayes: tidy data and geoms for Bayesian models. R package version 1.1.0. http://mjskay.github.io/ tidybayes/

Kazama K, Harada T, Deguchi T, Suzuki H, Watanuki Y (2019) Foraging behavior of black-footed albatross Phoebastria nigripes rearing chicks on the Ogasawara Islands. Ornitholog Sci 18:27-37

Kruschke JK, Liddell TM (2018) The Bayesian new statistics: hypothesis testing, estimation, meta-analysis, and power analysis from a Bayesian perspective. Psychon Bull Rev 25:178-206

Lajeunesse MJ (2011) On the meta-analysis of response ratios for studies with correlated and multi-group designs. Ecology 92:2049-2055

* Løkkeborg S (2011) Best practices to mitigate seabird bycatch in longline, trawl and gillnet fisheries-efficiency and practical applicability. Mar Ecol Prog Ser 435: 285-303

McCormack E, Papworth W (2014) Review of evidence of injuries sustained by fishers in the course of using weighted lines in pelagic longline fisheries. SBWG6 Document 15. Agreement on the Conservation of Albatrosses and Petrels, Hobart

McCormack E, Rawlinson N (2016) The relative safety of the Agreement on the Conservation of Albatrosses and Petrels (ACAP) recommended minimum specifications for the weighting of branchlines during simulated flybacks. ACAP-SBWG7-Doc8. Agreement on the Conservation of Albatrosses and Petrels, Hobart

Melvin E, Guy T, Read L (2013) Reducing seabird bycatch in the South African tuna fishery using bird-scaring lines, branch line weighting and nighttime setting of hooks. Fish Res 147:72-82

Melvin E, Guy T, Read L (2014) Best practice seabird bycatch mitigation for pelagic longline fisheries targeting tuna and related species. Fish Res 149:5-18

NMFS (2017) 2015 Annual Report. Seabird interactions and mitigation efforts in Hawaii longline fisheries. National Marine Fisheries Service, Pacific Islands Regional Office, Honolulu, HI

* Phillips RA, Gales R, Baker GB, Double MC and others (2016) The conservation status and priorities for albatrosses and large petrels. Biol Conserv 201:169-183

Pierre J, Goad D, Abraham E (2015) Novel approaches to line-weighting in New Zealand's inshore surface-longline fishery. Dragonfly Data Science, Wellington

Prince P, Huin N, Weimerskirch H (1994) Diving depths of albatrosses. Antarct Sci 6:353-354 
Rawlinson N, Haddy J, Williams M, Milne D, Ngwenya E, Filleul M (2018) The relative safety of weighted branchlines during simulated fly-backs (cut-offs and tear-outs). AMC Research, Launceston

Robertson G, Candy S, Hall S (2013) New branch line weighting regimes to reduce the risk of seabird mortality in pelagic longline fisheries without affecting fish catch. Aquat Conserv 23:885-900

Santos R, Silva-Costa A, Santana R, Gianuca D, Yates O, Marques C, Neves T (2019) Improved line weighting reduces seabird bycatch without affecting fish catch in the Brazilian pelagic longline fishery. Aquat Conserv 29:442-449

Schild AHE, Voracek M (2015) Finding your way out of the forest without a trail of bread crumbs: development and evaluation of two novel displays of forest plots. Res Synth Methods 6:74-86

US Government (2018) Code of Federal Regulations. Title 50-Wildlife and Fisheries. Vol 13. Section 665.813Western Pacific Longline Fishing Restrictions. https:// www.govinfo.gov/content/pkg/CFR-2018-title50-vol13/ xml/CFR-2018-title50-vol13-sec665-813.xml (accessed 5 November 2019)

Editorial responsibility: Rebecca Lewison, San Diego, California, USA van Helmond ATM, Mortensen LO, Plet-Hansen KS, Ulrich $\mathrm{C}$ and others (2020) Electronic monitoring in fisheries: lessons from global experiences and future opportunities. Fish Fish 21:162-189

* van Houwelingen HC, Arends LR, Stijnen T (2002) Advanced methods in meta-analysis: multivariate approach and meta-regression. Stat Med 21:589-624

* Véran S, Gimenez O, Flint E, Kendall W, Doherty P Jr, Lebreton J (2007) Quantifying the impact of longline fisheries on adult survival in the black-footed albatross. J Appl Ecol 44:942-952

*Viechtbauer W (2010) Conducting meta-analyses in R with the metafor package. J Stat Softw 36:1-48

*Ward P, Lawrence E, Darbyshire R, Hindmarsh S (2008) Large-scale experiment shows that nylon leaders reduce shark bycatch and benefit pelagic longline fishers. Fish Res 90:100-108

WCPFC (Western and Central Pacific Fisheries Commission) (2018) Conservation and management measure to mitigate the impact of fishing for highly migratory fish stocks on seabirds. CMM 2018-03. Western and Central Pacific Fisheries Commission, Kolonia

Submitted: May 27, 2020; Accepted: August 24, 2020

Proofs received from author(s): October 2, 2020 